\title{
Acute Back Syndrome-A Study from General Practice
}

\author{
J. B. DILLANE,* F.R.C.S. ; JOHN FRY,* M.D., F.R.C.S. ; G. KALTON, $\dagger$ M.SC.(ECON.)
}

Brit. med. F., 1966, 2, 82-84

Although the acute back syndrome, lumbago, or acute lower backache is such a common problem in general practice and an important cause of industrial disability (Troup, 1965), little discussion of it is given in the standard textbooks of orthopaedics. As the aetiology, pathology, and prognosis are all obscure, this lack of attention is understandable. To many minds acute lower back pain, with or without sciatica, suggests as a first possibility prolapsed lumbar intervertebral disc; to others the "osteopathic lesion" is the common explanation (Stoddard, 1959).

This paper represents an attempt to measure the incidence of "acute backs" in one general practice and to note if a cause such as back strain is often present. An effort has also been made to discover if any aspects of the clinical condition have a significant influence on the duration of the initial attack or the liability to recurrence.

\section{Methods}

The population studied comprised all the patients of a suburban general practice in South-east London. A $10 \%$ sample of patients in 1961 showed that the majority were middle-class: in fact only $11.5 \%$ of the 191 economically active and retired males in the sample were in the RegistrarGeneral's Social Classes IV and V (General Register Office, 1960), while in England and Wales generally the proportion is about two and a half times as large.

In addition to comprehensive clinical records punched cards (Cope-Chat) were kept for each patient. On these cards a 12months record of a patient's morbidity experience under broad diagnostic categories was kept, a new card being introduced at the beginning of each calendar year. In preparation for this study one position on the card was reserved for recording whether the patient suffered an attack of the acute back syndrome, which was defined as a sudden low backache severe enough for the patient to seek medical advice. While an analysis of the Cope-Chat cards included all cases of acute lower backache seen during the period of study, only the N.H.S. records of those patients still on the practice list were available for analysis.

The results are presented in two parts. First, the incidence study was conducted by observing all the attacks recorded on the Cope-Chat cards during the four calendar years 1957-60, with an annually maintained age-sex register providing the basic information of the patients exposed to risk. The incidence study thus located all the patients who had experienced backache during 1957-60. Secondly, the follow-up study was concerned only with those patients who had experienced an attack of acute backache in the incidence study and who were still in the practice at the time of analysis (January 1965); for these patients the more detailed clinical information on the N.H.S. records was available. All such patients were followed up for a period of four years from the onset of their first attack in the incidence study, to observe whether they experienced any further attacks. The follow-up study therefore continued for a number of cases until late 1964.

* General practitioner, Beckenham, Kent.

t London School of Economics.

\section{Incidence Study}

During the four-year period of the incidence study 605 attacks of backache were recorded. Analysis of these attacks in terms of inception rates introduced several problems.

First, there was the problem of a denominator for the rate ; during the four years the practice did not remain of constant size, but increased steadily from 5,713 patients at the beginning of 1957 to 6,920 at the end of 1960 . In order to use an annual inception rate, the denominator should be the total number of patient-years for which patients were exposed to risk; this quantity has been estimated by

$\frac{1}{2} \mathrm{~N}(1957)+\mathrm{N}(1958)+\mathrm{N}(1959)+\mathrm{N}(1960)+\frac{1}{2} \mathrm{~N}(1961)$

where $N$ (1957) denotes the number of patients on the age-sex register at 1 January 1957, with a similar definition for the other terms.

Secondly, it was necessary to distinguish between an inception rate (spells) and an inception rate (persons)-the terms of the Statistics Subcommittee of the Registrar-General's Advisory Committee on Medical Nomenclature and Statistics being used (General Register Officer, 1954). The numerator for the former rate is the total number of spells, while for the latter it is the total number of persons experiencing spells. Thus a person with two spells counts as one person in the inception rate (persons) but as two spells in the inception rate (spells). A further complication arose in this study because the period of observation was not the same as the period for the rate. In the event, however, there were only a few cases where a patient had more than one attack during a calendar year, and the majority had only one attack in the four years of the incidence study. For these reasons, only the full details of the inception rate (spells) are given in Table I.

TABLE I.-Inception Rate (Spells) of Backache per 1,000 Patient-years at

\begin{tabular}{|c|c|c|c|c|c|c|}
\hline \multirow[b]{3}{*}{$\begin{array}{c}\text { Age } \\
\text { (Years) }\end{array}$} & \multicolumn{6}{|c|}{ KISR } \\
\hline & \multicolumn{3}{|c|}{ Males } & \multicolumn{3}{|c|}{ Females } \\
\hline & $\begin{array}{l}\text { No. of } \\
\text { Attacks }\end{array}$ & $\begin{array}{c}\text { Patient- } \\
\text { years } \\
\text { at } \\
\text { Risk }\end{array}$ & $\begin{array}{c}\text { Rate } \\
\text { per 1,000 } \\
\text { Patient- } \\
\text { Years }\end{array}$ & $\begin{array}{l}\text { No. of } \\
\text { Attacks }\end{array}$ & $\begin{array}{c}\text { Patient- } \\
\text { years } \\
\text { at } \\
\text { Risk }\end{array}$ & $\begin{array}{c}\text { Rate } \\
\text { per } 1,000 \\
\text { Patient- } \\
\text { years }\end{array}$ \\
\hline $\begin{array}{l}0- \\
10- \\
20- \\
30- \\
40- \\
50- \\
60- \\
70- \\
80-\end{array}$ & $\begin{array}{r}0 \\
5 \\
30 \\
62 \\
76 \\
90 \\
44 \\
12 \\
3\end{array}$ & $\begin{array}{c}1,790 \\
1,785 \\
1,417 \\
2,092 \frac{1}{2} \\
1,885 \\
1,671 \\
1,046 \\
463 \frac{1}{2} \\
156\end{array}$ & $\begin{array}{r}0 \cdot 0 \\
2 \cdot 8 \\
21 \cdot 2 \\
29 \cdot 6 \\
40 \cdot 3 \\
53.9 \\
42 \cdot 1 \\
25.9 \\
19 \cdot 2\end{array}$ & $\begin{array}{r}0 \\
4 \\
32 \\
56 \\
58 \\
82 \\
43 \\
8 \\
0\end{array}$ & $\begin{array}{c}1,883 \\
1,582 \\
1,750 \\
2,099 \\
1,808 \frac{1}{2} \\
1,696 \\
1,233 \\
463 \frac{1}{2} \\
156\end{array}$ & $\begin{array}{r}0.0 \\
2.5 \\
18 \cdot 3 \\
26 \cdot 7 \\
32 \cdot 1 \\
48 \cdot 3 \\
34.9 \\
17 \cdot 3 \\
0.0\end{array}$ \\
\hline$\overline{\text { All ages }}$ & 322 & 12,306 & $26 \cdot 2$ & 283 & 12,671 & $22 \cdot 3$ \\
\hline
\end{tabular}

Over the whole practice population there were 24.2 attacks per 1,000 patient-years at risk. For both males and females there was a marked variation by age, with a peak occurring in age group 50-59 years; in fact the rate for this group was just over twice the overall average rate. In each age group the men exhibit a slightly higher rate than the women.

During the four years of study there were 605 attacks, but only 470 patients ( 247 males and 223 females) suffered attacks; the average numbers of attacks per person attacked were 1.30 for men and 1.27 for women. By relating the numbers of persons suffering attacks to the average size of the practice during the four-year period the four-year inception rate (persons) was obtained; for men this rate was 80.3 per 
1,000 and for women 70.4 per 1,000. The annual inception rate (persons) was 24.3 per 1,000 for males and 20.6 per 1,000 for females.

\section{Follow-up Study}

At the time of analysis $74.5 \%$ of the males and $72.2 \%$ of the females who experienced an attack during the incidence study were still in the practice. A higher rate of leaving occurred in the younger age groups, where 24 of the 51 patients under 30 years old had left the practice.

The cause of the index attack-that is, the first attack in the four years of the incidence study-is given in Table II. It shows that there was no definite ascertainable cause in the great majority of cases ; only $10.9 \%$ of men and $4.3 \%$ of women gave a history of a causal strain, and prolapsed lumbar intervertebral disc, as defined above, would seem to be an unimportant cause of acute low back pain in general practice. Serious disease was rare.

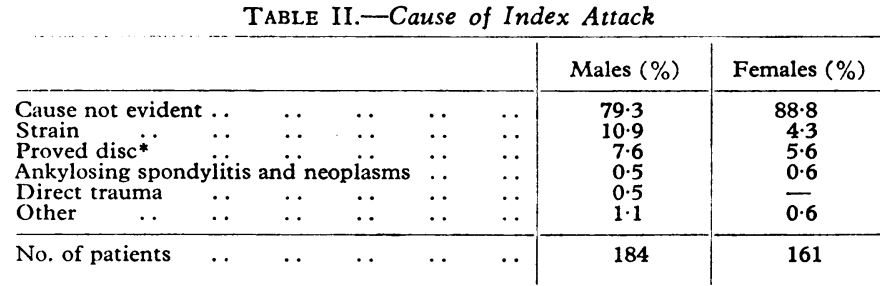

* A diagnosis of prolapsed disc was accepted only if there was objective evidence of nerve-root pressure-paralysis or wasting of muscle or an area of anaesthesia. $X$-ray evidence of "disc" is known to be unreliable (Troup, 1965).

In the $10 \%$ sample of male patients in the practice in 1961 $57 \%$ of the 191 economically active and retired males were in the Registrar-General's Socio-Economic groups 1-6, which are non-manual occupations, whereas in an industrial conurbation like Merseyside the proportion of non-manual workers is only about half of this percentage. Despite the low proportion of manual workers in the practice there was still a considerable annual incidence of acute lower backache.

The duration of the index attack (Table III) was measured by the time between the first and the last consultation. Naturally those patients who were directed to hospital supervision may have been lost sight of, but, as is shown below, this involved only a very small proportion. As Table III shows, the index attacks were often of short duration, $62 \%$ lasting less than two weeks.

TABLE III.-Duration of Index Attack

\begin{tabular}{|c|c|c|c|}
\hline \multicolumn{2}{|l|}{ Duration } & Ma'es (\%) & Females (\%) \\
\hline $\begin{array}{l}\text { Under } 1 \text { week } \\
1 \text { week- } \quad \ldots \\
2 \text { weeks- } \quad \ldots \\
3 \text { " } \\
4 \text { months and } \\
2 \text { over }\end{array}$ & $\begin{array}{ll}\cdots & \cdots \\
\cdots & \cdots \\
\cdots & \cdots \\
\cdots & \cdots \\
\cdots & \cdots\end{array}$ & $\begin{array}{r}44 \cdot 0 \\
16 \cdot 3 \\
11 \cdot 4 \\
12 \cdot 5 \\
7 \cdot 6 \\
8 \cdot 2\end{array}$ & $\begin{aligned} 44 \cdot 1 \\
21 \cdot 1 \\
12 \cdot 4 \\
8 \cdot 7 \\
8 \cdot 7 \\
5 \cdot 0\end{aligned}$ \\
\hline No. of patients & .. & 184 & 161 \\
\hline
\end{tabular}

In looking for factors related to the duration of index attacks there was found to be no significant variation in duration by age: $33.3 \%$ of patients aged under $30,37.6 \%$ of those aged $30-59$, and $40.9 \%$ of those aged 60 and over had attacks lasting two weeks or more $\left(\chi^{2}=0.53 ; 2\right.$ d.f. ; not significant). Referred pain (usually sciatica) occurred in $21.7 \%$ of men and $28.0 \%$ of women, but had no significant influence on the time taken for the attack to resolve: $34.7 \%$ of patients without referred pain had attacks lasting two weeks or more, compared with $45.9 \%$ of patients with referred pain $\left(\chi^{2}=2.93 ; 1\right.$ d.f. ; not significant)

On the other hand, in 17 (74\%) of 23 patients with objective evidence of nerve-root pressure the attack lasted for two weeks or more ; when there was no evidence of nerve-root pressure only $35 \%$ of attacks were so prolonged. The difference is highly significant $\left(\chi^{2}=12.33 ; 1\right.$ d.f. ; $\left.\mathrm{P}<0.01\right)$.

\section{Treatment}

In this practice symptomatic treatment-rest, heat, liniment, and aspirin-was always tried first. If the attack was prolonged the patient was often referred to hospital, because the general practitioners have no direct facilities for physiotherapy. Table IV shows that in $90 \%$ of cases only symptomatic treatment was needed. It also shows the eventual management of the $11.4 \%$ of men and $6.9 \%$ of women referred to hospital.

TABLB IV.-Treatment of Index Attack

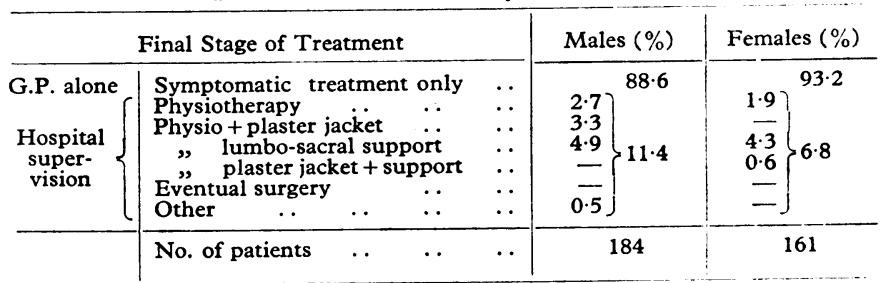

Incidentally $83.9 \%$ of males and $86.4 \%$ of females were able to attend the consulting-room for every consultation associated with the attack, and so did not require a home visit.

\section{Recurrences}

The four-year follow-up study made it possible to investigate whether any factors were associated with recurrence. Since only a very small number had two or more further attacks, the patients have been divided into two groups-those experiencing at least one further attack within four years of their index attack and those experiencing no further attack during that period.

The first point to note is that a high proportion of the patients did have a further attack: $44.6 \%$ of those with an index attack had a recurrence within four years. On the basis of the age-and-sex-specific four-year inception rates obtained in the incidence study, the proportion of patients in the followup who might have been expected to suffer a further attack was only $11.0 \%$. It thus appears that certain persons are prone to the condition of acute lower backache.

The proportions of males and females having further attack were very similar : $46.7 \%$ of males and $42.2 \%$ of females had a further attack $\left(\chi^{2}=0.53 ; 1\right.$ d.f. ; not significant). Table V shows that there was no significant difference between the ages of the two groups $\left(\chi^{2}=0.53 ; 2\right.$ d.f. ; not significant).

TABLE V.-Age Distribution of Patients Having at Least One Further

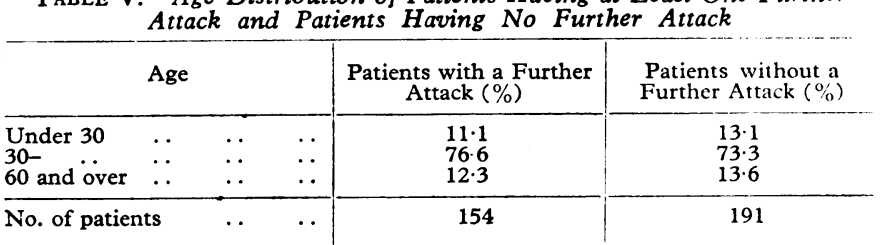

Thus the general demographic characteristics of the patients did not help to distinguish those liable to a further attack. It was necessary, therefore, to consider whether any of the information obtained about the index attack would assist in differentiating between the two groups. The data on cause were of little use, since, as shown above, nearly all the cases had to be described by "cause not evident." Nevertheless, " proved disc" was significantly associated with recurrence: of the 23 cases of "proved disc" on the index attack 17 (74\%) had a recurrence, the corresponding proportion for those with no "proved disc" being only $42.5 \%\left(\chi^{2}=7.33 ; 1\right.$ d.f.; $\left.\mathrm{P}<0.01\right)$.

On the other hand, the presence of referred pain with the index attack was no guide to the liability to recurrences. Of the patients suffering a further attack $28.8 \%$ had referred pain 
with the index attack, and for patients with no further attack the corresponding proportion was $21.6 \%\left(\chi^{2}=1.95 ; 1\right.$ d.f. ; not significant). This result is in keeping with Kellgren's (1938) finding that referred pain can arise from superficial structures in the back, and does not therefore mean that there is pressure on nerve roots. Of the 85 patients with referred pain, only 9 $(10.6 \%)$ had a "proved disc." Moreover, $14(61 \%)$ of the 23 patients with "proved disc" did not experience referred pain.

The duration of the index attack was significant in assessing the liability to recurrence. In the group of patients with no recurrences $68.1 \%$ of index attacks lasted less than two weeks, compared with $55.6 \%$ for the group who did have further attacks $\left(\chi^{2}=5.15 ; 1\right.$ d.f. ; $\left.\mathrm{P}<0.05\right)$.

While the statistical analysis shows that those who had further attacks tended to have longer index attacks, requiring more treatment than was the case with those having no further attack, the tendency was not particularly strong; in other words, this type of information on the index attack is of little value in attempting to identify patients likely to have further attacks. For example, one could use the criterion that any patient whose index attack lasts more than four weeks is liable to a further attack; in this study the duration of the index attack exceeded four weeks for 52 patients, but only $59.6 \%$ of these had a further attack within four years-a figure which is not much larger than the $44.6 \%$ of all patients who had a further attack.

\section{Conclusions and Summary}

Acute lower backache often occurs in general practice. Over a period of four years $7.5 \%$ of the population at risk in the practice studied consulted the doctors with this complaint.
The overall annual inception rate was 24.3 per 1,000 in males and 20.3 per 1,000 in females, but there was considerable variation by age. A peak in both males and females occurred in the 50-59 decade, this age group experiencing twice the overall inception rate.

No cause was evident for the attacks in $79.3 \%$ of males and in $88.8 \%$ of females ; there was a recent history of strain in only $10.9 \%$ of males and $4.3 \%$ of females, and only a small proportion of patients had definite evidence of nerve-root pressure (7.6\% of males and $5.6 \%$ of females).

The majority of the attacks were of short duration, lasting less than two weeks in $62 \%$ of cases. The duration of the attacks was not significantly related to age or sex, nor to the presence of referred pain, but it was related to the presence of objective signs of root pressure. Ninety per cent of the attacks were managed by the general practitioners, who used only symptomatic treatment.

Recurrences were not related to age, sex, or the presence of referred pain, but were more likely to occur in patients diagnosed as having nerve-root pressure and in those whose index attack lasted longer than two weeks.

Of the patients identified by an attack during the incidence study $44.6 \%$ had a recurrence within four years, which is almost four times the rate expected in a group with the same age and sex distribution

REPERENCES

Kellgren, J. H. (1938). Clin. Sci., 3, 175.

General Regíster Office (1954). Medical and Population Subjects Study No. 8. Measurement of Morbidity. H.M.S.O., London.

Stoddard, A. (1959). Manual of Osteopathic Technique. Hutchinson, London.

Troup, J. D. G. (1965). Lancet, 1, 857.
K. T. SHETTY,* M.D. ; N. L. SHARMA, $†$ M.D., D.C.H., D.T.M., D.P.H. ; K. M. WAHAL, $\ddagger$ M.D., D.SC.

Brit. med. F., 1966, 2, 84-86
* Reader in Paediatrics, Kasturba Medical College, Manipal, South India. t Professor of Paediatrics, King George's Medical College, Lucknow, India.

It has been proved that the sex-chromatin body is derived from one of the two $\mathrm{X}$ chromosomes in the female which replicates its deoxyribonucleic acid much later than the other and is thus positively heteropyknotic (Ohno et al., 1959). It has also been suggested that one diploid set of autosomes prevents the formation of sex-chromatin mass from one $\mathrm{X}$ chromosome, the Barr body being derived from any additional uninhibited $\mathrm{X}$ chromosome (Ohno et al., 1959 ; Harnden, 1961). On the other hand, Mary Lyon's (1961) hypothesis-that the choice of which of the two X chromosomes is to be inactivated has to be made at a definite point in foetal development, that it is a choice made at random and independently by each cell present at this time, and that once made it is irreversible and transmittable to all descendants of the cell-is very fascinating. administration has been reported by Sohval and Casselman (1961). A decreased incidence of sex-chromatin-positive cells in females treated with cortisone has also been reported (Taylor, 1961). We have therefore undertaken a systematic study of the incidence of sex-chromatin mass in cortisone-treated female children.

¥ Reader in Pathology, King Ceorge's Medical College, Lucknow, India.
An alteration in the size of the Barr body on antibiotic

\section{Material and Methods}

One hundred healthy girls and 100 healthy boys who had not been on any form of drug therapy for the previous six months were studied as a control group. Sixty-seven female patients of the Children's Hospital, Lucknow, who were being treated with prednisone for various diseases, such as tuberculous meningitis, acute rheumatic carditis, liver-cell failure, hypoplastic anaemia, encephalitis, nephrotic syndrome, enteric fever, bronchopneumonia, etc., were used for the study.

The staining method of Klinger and Ludwig as modified by Barr (1960) was employed. For consistency in results only those nuclei lying against the nuclear membrane were scored as positive.

Two smears were taken from each subject (including the controls) each time the study was made, and 500 cells were counted for each subject and the percentage incidence of sex chromatin was calculated. Whenever too many cells were shrunken, folded, or pyknotic, or if there was much bacterial contamination, fresh smears were examined.

All the slides were coded, and the control slides were mixed with the slides of the prednisone-treated children so that the reading of the slides was "blind." 